\title{
Prediction of left heart filling pressure and its sequential change in acute myocardial infarction from the terminal force of the $\mathrm{P}$ wave ${ }^{1}$
}

\author{
Juhani Heikkilä, Paul G. Hugenholtz, and Burton S. Tabakin \\ From Coronary Care Unit, Thoraxcentre, University Hospital Rotterdam, Rotterdam, The Netherlands
}

Left ventricular filling pressure serves as a most useful haemodynamic index of cardiac dysfunction in acute myocardial infarction. In order to predict the filling pressure from the $P$ wave of the electrocardiogram, flowdirected Swan-Ganz catheters were inserted in 40 acutely ill patients (36 with acute myocardial infarction or serious angina). An elementary electrocardiographic measurement, the $P$ terminal force in lead VI was found to be well and inversely correlated to the level of mean left ventricular filling pressure, particularly in patients with acute left heart failure $(P<0.001, r=-0.82)$. Significant correlation $(P<0.001)$ was further noted between left ventricular filling pressure and clinical severity of acute myocardial infarction, mixed venous oxygen saturation, pulmonary râles, and radiological pulmonary vascular congestion. Absence of third and fourth heart sounds indicated normal left ventricular filling pressure in acute myocardial infarction but the reverse was not found to be true. Acute sequential variations in left ventricular filling pressure were paralleled by the $P$ terminal force more closely than any other recorded variable.

It is concluded that $P$ wave alterations provide a useful, simple, and noninvasive tool for quantitative assessment of acute changes in $L V$ preload in seriously ill patients.

Continuous observation and prompt treatment in coronary care units of the electrical instability in acute ischaemic heart disease has made death, as a consequence of the arrhythmia per se, rare. Consequently, mechanical pump failure is now the most common cause of hospital death in patients with acute myocardial infarction. Prediction and correct treatment of the pathophysiological derangements in this type of failure in the heart have therefore emerged as of paramount importance in the effort to reduce deaths secondary to acute myocardial infarction.

Parameters commonly used in attempts to assess power failure have been those derived from the usual clinical observations, palpation, and auscultation. More recently these have been supplemented by the more quantitative measurement of pulmonary arterial pressure and pulmonary capillary wedge pressure, reflecting left ventricular filling pressure, by means of the Swan-Ganz balloon-type catheter. Other workers have reported on the use of mixed

Received 4 August 1972.

1 The present work was presented in abstract form in Circulation, 44, Suppl. 2, 23I, I97I. venous oxygen saturation, repeated chest $x$-ray films, and the determination of cardiac output and other haemodynamic parameters. However, there remains a need for a simple and easily repeatable noninvasive method for the early prediction of impending power failure, particularly when several patients are simultaneously monitored in the coronary care unit.

Earlier clinical investigations have suggested that acute changes in the $P$ wave configuration give information of acutely developing left ventricular (LV) dysfunction in acute myocardial infarction (Heikkilā, 1967; Heikkilä and Luomanmäki, 1970). Therefore, the reliability of this electrocardiographic indicator of left atrial overloading was examined for its ability to predict one major haemodynamic factor, the left heart filling pressure, by the correlation of serial changes of the $P$ wave with pressures, simultaneously measured through a catheter in the pulmonary capillary wedge position.

Severity of acute infarction was also assessed clinically, by auscultatory evidence for left ventricular failure, by the degree of pulmonary vascular congestion and heart size on the chest film, and by 
pulmonary arterial oxygen saturation measured intermittently. These parameters were likewise related to serially measured filling pressures.

\section{Patients and methods}

The study comprised 40 acutely ill patients admitted to the Coronary Care Unit of the University Hospital, Rotterdam. Thirty-six of them had acute ischaemic heart disease; 29 of these had acute myocardial infarction, and 7 prolonged angina pectoris. Four patients with, respectively, aortic stenosis, tight mitral stenosis complicated by acute pulmonary oedema, complete heart block, and noncardiac chest pains were also included. There were 5 women and 35 men. The mean age was $57 \cdot 2$ years, with a range of 28 to 78 years.

\section{Clinical classification}

The patients were grouped according to the clinical assessment of the severity of acute myocardial infarction or left ventricular failure into 3 groups, as defined earlier (Heikkilä, Luomanmäki, and Pyörälä, I97ra): Group I formed the nonfailure group, and consisted of 4 patients with uncomplicated acute myocardial infarction, 7 with angina pectoris, and 2 of the noncoronary patients; none of these 13 in group I had clinical signs of heart failure during their entire observation period. Group 2 consisted of 12 patients with moderately severe acute myocardial infarction. Group 3 was made up of 15 patients (13 with acute myocardial infarction) who had pulmonary oedema or cardiogenic shock.

The clinical examination was carried out once or more daily. The recorded signs included the presence or absence of pulmonary râles, atrial $\left(\mathrm{S}_{4}\right)$ or ventricular (S3) added sounds, paradoxical cardiac pulsation, and auscultatory evidence for papillary muscle dysfunction. The criteria for recognition of these signs of left ventricular dysfunction have been described in detail (Heikkilä, 1967; Heikkilä et al., 197ra). Five patients died, 4 in cardiogenic shock and I from the rupture of a dissecting aorta.

\section{Electrocardiograms}

A direct writing, heated stylus, Hewlett Packard I513A 3-channel electrocardiograph with linear response to 80 c.p.s. was used to record I2-lead electrocardiograms in the usual fashion. Records were made daily for the first 5 days, and then whenever the clinical situation indicated its need for as long as 9 days. Since patients with pulmonary oedema are generally treated in a half-sitting position, it is important to note that these electrocardiograms were recorded in supine position to obtain correct data. The paper speed was $25 \mathrm{~mm} / \mathrm{sec}$, and the gain setting such that Io $\mathrm{mm}$ deflection equalled I $\mathrm{mV}$ calibration. Only the $\mathbf{P}$ terminal force in lead VI was selected for the analysis, as earlier studies indicated this parameter to be one of the most sensitive electrocardiographic parameters for predicting left atrial overload (Morris et al., I964; Saunders et al., I967; Kasser and Kennedy, 1969; Heikkilä and Luomanmäki, 1970). $\mathbf{P}$ wave terminal force was determined from the duration

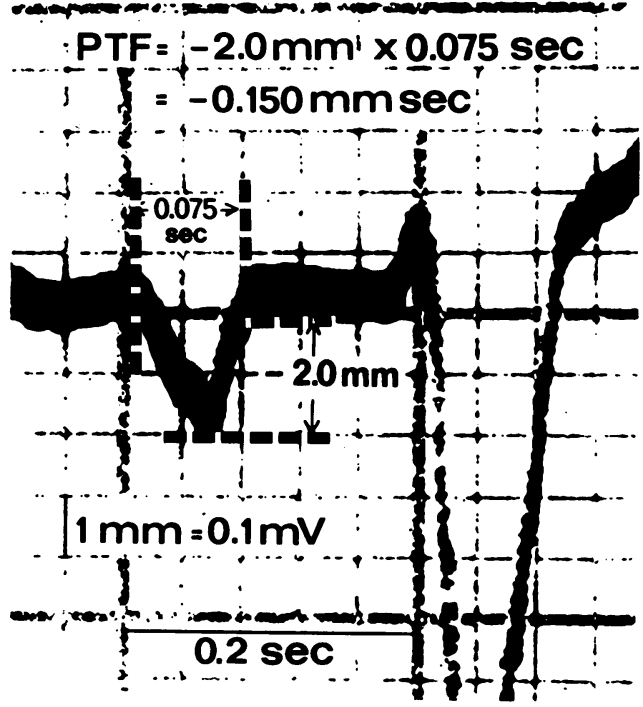

FIG. I Measurements of the duration and amplitude of the negative deflection of the $P$ wave in lead VI for calculation of $P$ terminal force $(P T F)$.

and amplitude of the terminal deflection of the $\mathbf{P}$ wave in lead VI, as described originally by Morris et al. (1964). A special fine line grid was used to increase the accuracy of measurement (Heikkilä, I967) (Fig. I). The average value of 5 electrocardiographic complexes was taken in order to avoid the effect of respiratory changes.

\section{Chest $X$-ray films}

Good quality bedside $x$-ray pictures were available from a Philips portable $x$-ray unit in 38 of the 40 patients. These were exposed with a I $\mathrm{m}$ focus-film distance daily for the first three days and thereafter whenever clinical conditions demanded it. A cardiothoracic ratio over 55 per cent was considered abnormal. Pulmonary vascular congestion was carefully assessed from the films without earlier knowledge of the clinical or haemodynamic data.

The following scoring was used (Heikkilä, 1967).

o- normal pulmonary vascular structures with distinct borders.

I - pulmonary venous distension only.

2 - interstitial oedema.

3 - reversed vascular pattern of lower field vasoconstriction and upper field vasodilatation, septal lines.

4 - widespread alveolar oedema.

\section{Pulmonary artery and pulmonary capillary wedge pressures}

In every patient a Swan-Ganz $5 \mathrm{~F}$ flow-directed doublelumen balloon catheter was inserted on admission to 


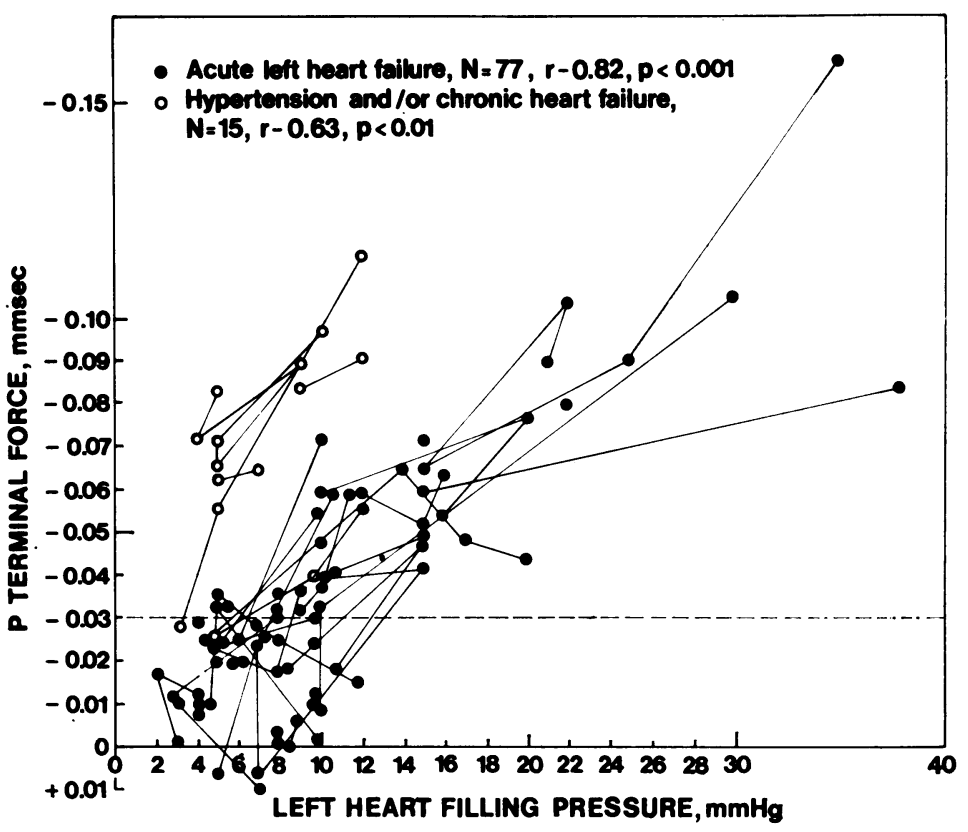

FIG. 2 Relation between $P$ terminal force and left heart filling pressure in 32 patients (23 with acute myocardial infarction) (92 observations).

the coronary care unit. The catheter was floated rapidly, without significant arrhythmias, into a peripheral branch of the pulmonary artery so that the pulmonary capillary wedge pressure could be measured whenever the balloon was reinflated (Swan et al., 1970b). The pulmonary capillary wedge mean pressure from beats over several respiratory cycles was averaged. In an occasional case where the wedge pressure could not be measured, pulmonary artery diastolic pressure was used as an equivalent. Such substitution has been shown to be valid for patients without chronic pulmonary vascular disease (Lassers et al., 1970; Russell et al., 1970; Karliner and Ross, 1971). Serial pressure measurements were done every $I$ to 2 hours in each patient. An average of 4 comparisons with simultaneous electrocardiograms were analysed per patient. The zero reference level was taken to be $5 \mathrm{~cm}$ below the sternal angle. A Statham $23 \mathrm{~dB}$ pressure transducer, and a Philips or Hewlett Packard preamplifier and inkjet recorder were employed for these measurements and recordings. In this study pulmonary capillary wedge pressure was considered to be equivalent to the left heart filling pressure.

\section{Pulmonary arterial oxygen saturation}

Blood samples withdrawn through pulmonary catheters were analysed by the American Optical direct oximeter in the coronary care unit.

\section{Results}

\section{Relation of $P$ terminal force to left heart filling pressure}

Pulmonary capillary wedge and/or pulmonary arterial diastolic pressure were available in 77 instances from 27 patients in whom left ventricular dysfunction developed acutely. Comparison of mean pulmonary capillary wedge and $P$ terminal force in this group had a correlation coefficient of $r=-0.82$, $P<0.001$ (Fig. 2). The regression equation was: PCW = 3.7-r9I PTF (mm sec) \pm 4.0 (Sy, $x$ ) mmHg. The electrocardiogram was always abnormal, i.e. $P$ terminal force less than $-0.03 \mathrm{~mm} \mathrm{sec}$, if pulmonary capillary wedge exceeded $12 \mathrm{mmHg}$. If it was below Io $\mathrm{mmHg}, \mathrm{P}$ terminal force remained either normal or occasionally was borderline abnormal, i.e. between $-0.03 \mathrm{~mm}$ sec and -0.04 mm sec.

Five patients had longstanding hypertension and/ or chronic heart failure and were admitted due to acute worsening of their clinical state. These 5 patients often had abnormal $P$ terminal force despite normal filling pressure (Fig. 2); the regression line $(r=-0.63 ; P<0.01)$ was steeper than when left ventricular dysfunction developed acutely. 


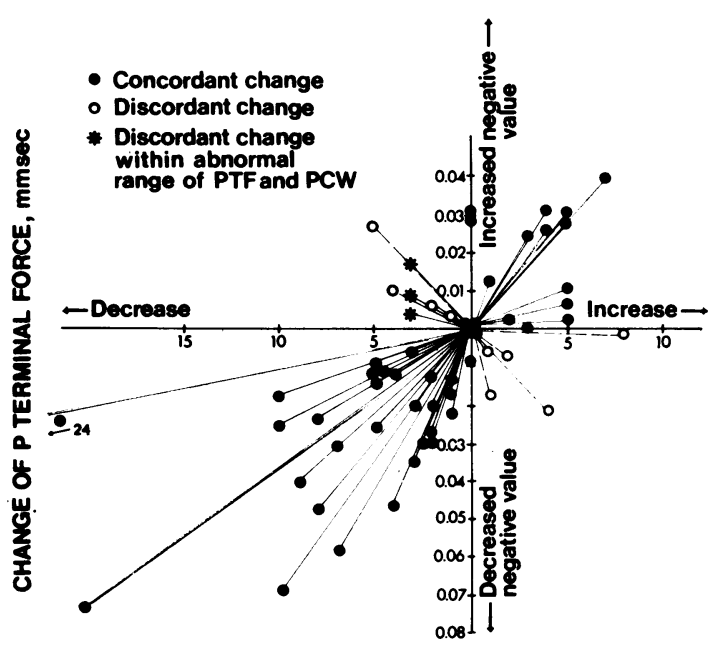

CHANGE OF LEFT HEART FILLING PRESSURE, $\mathrm{mmHg}$

FIG. 3 Variations in pulmonary capillary wedge pressure are predictable by electrocardiographic left atrial overload, particularly with high ranges of pulmonary capillary wedge pressure within a few hours.

\section{Sequential changes in LV filling pressure indi- cated by $\mathbf{P}$ terminal force}

Serial changes generally revealed a decrease in left ventricular filling pressure during treatment. In 46 comparisons the sequential pressure changes were associated with parallel changes in $\mathrm{P}$ terminal force. Discordant changes were only minor and were observed in 10 of 13 instances within the normal range for both these variables (Fig. 2 and 3). In the 3 remaining observations the range of the pulmonary capillary wedge changes was only $3 \mathrm{mmHg}$ or less (Fig. 3). It was striking to observe that $P$ terminal force paralleled acute variations in pulmonary capillary wedge over a wide range rapidly (Fig. 4): this frequently occurred within a period of just a few hours. Compared to other bedside findings of left ventricular dysfunction, such as the onset or disappearance of pulmonary râles, the presence of atrial or ventricular gallop sounds, or the radiological changes of pulmonary oedema, $P$ terminal force demonstrated changes in LV filling pressure much more rapidly and accurately than did any other recorded variables.

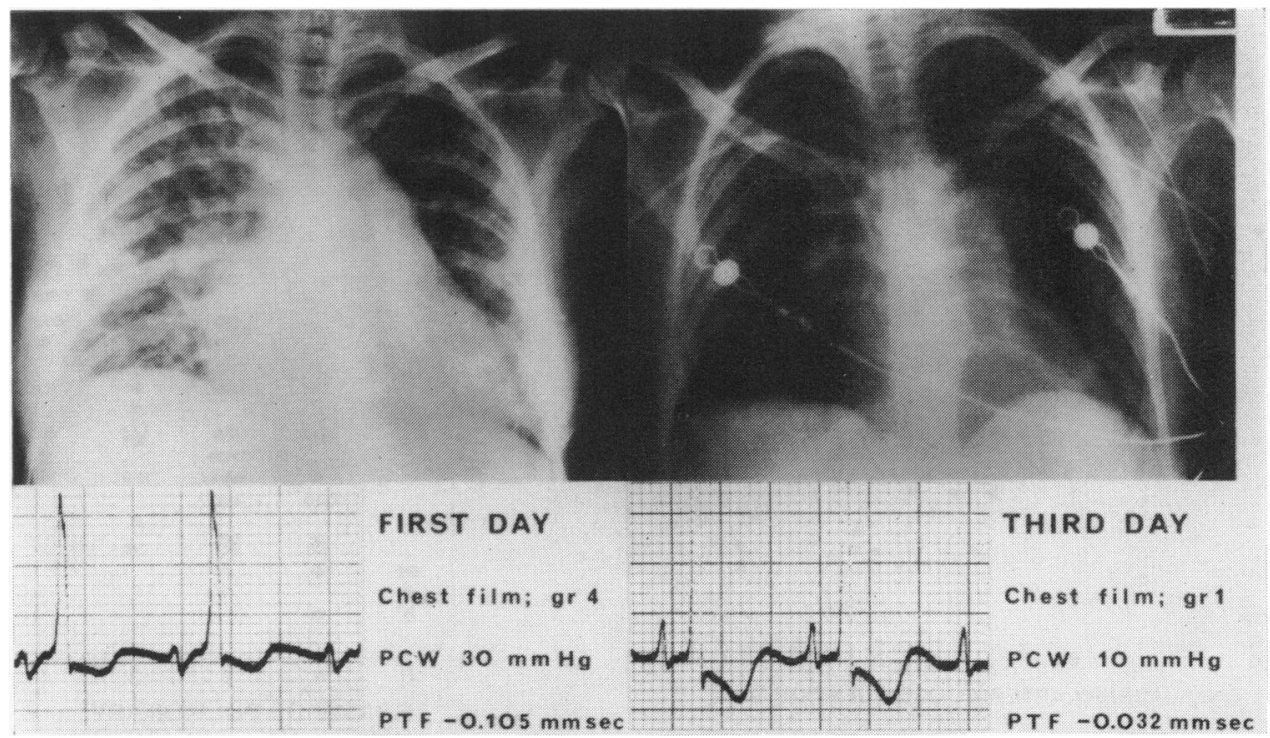

FIG. 4 A return to normal of pulmonary capillary wedge pressure is accompanied by concordant rapid return to normal of $P$ terminal force during treatment of pulmonary oedema patient with tight mitral stenosis and serious pulmonary hypertension. 


\section{Relation of $\mathbf{P}$ terminal force to pulmonary arterial mean pressures}

One hundred and thirty-four observations were made. For these as a whole the correlation of $P$ terminal force with pulmonary artery mean pressure was not so good as with pulmonary capillary wedge $(r=-0.48 ; P<0.001)$. However, $r$ equalled -0.64 , $\mathrm{P}<0.00 \mathrm{I}$, for the 104 observations made during acute cardiac failure; in the patients with chronic heart failure this correlation remained insignificant.

\section{Other findings in $\mathrm{LV}$ failure}

Only patients with pulmonary oedema had low (less than $60 \%$ ) pulmonary arterial oxygen saturations. Relation of pulmonary oxygen saturation to pulmonary capillary wedge pressure in 3I observations is shown in Fig. 5. The regression equation was $\mathrm{PCW}=44.2-0.49 \mathrm{O}_{2}$ sat. $(\%) \pm 3.3 \mathrm{mmHg}$, $r=-0.7 I, P<0.001$.

An enlarged heart was found by chest $\mathrm{x}$-ray film in 21 of 38 patients $(55 \%)$. The cardiothoracic ratio did not correlate with the pulmonary capillary wedge, nor with $\mathbf{P}$ terminal force though normal filling pressures were mostly found in normal-sized hearts. Completely normal vascular markings were found in the chest films of 2 patients $(5 \%)$ only. Grade I congestion occurred in 3 patients $(8 \%)$, grade 2 in $8(21 \%)$, grade 3 in $7(18 \%)$, and grade 4

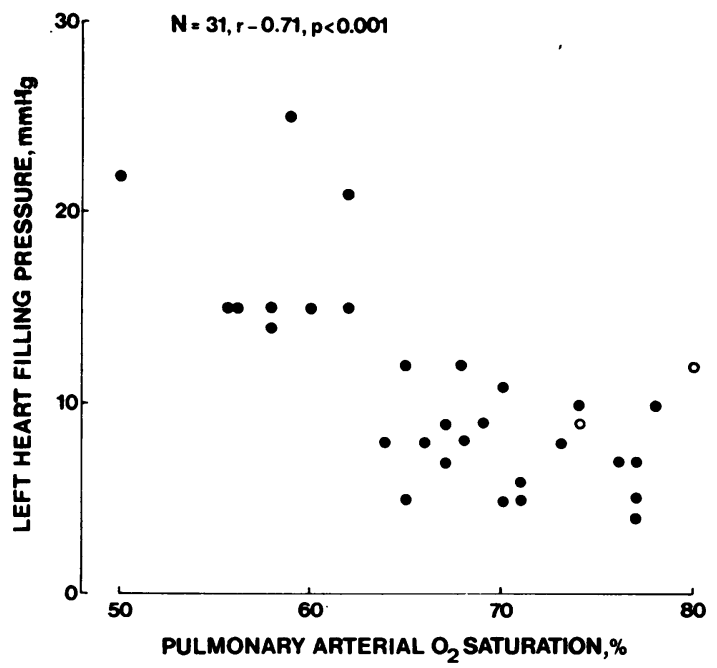

FIG. 5 Pulmonary arterial oxygen saturation plotted against mean left heart filling pressure. Note that saturation less than 60 per cent is always associated with abnormal pulmonary capillary wedge pressure. in 18 patients $(47 \%)$ in the 38 where $x$-ray studies were available. In 35 per cent of the patients with pulmonary oedema (grade 4) secondary to acute myocardial infarction a normal sized heart was present.

The association of radiological pulmonary venous congestion with LV filling pressure is shown in Fig. 6. The correlation coefficient was 0.63 ; $P<0.001$, in 65 observations. The 5 radiological classifications differed significantly from each other $(P<0.001)$ also when analysed by $F$ test $(F=15.16$, d.f. 4.60). The individual groups differed $(\mathrm{P}<0.00 \mathrm{I})$ from each other as shown in Fig. 6.

The level of the LV filling pressure was closely correlated with the previously described three clinical groups $(\mathrm{F}=24 \cdot 6, \mathrm{P}<0.001)$. Only cases with acute $\mathrm{LV}$ dysfunction are included in these figures. The mean of the highest pulmonary capillary wedge pressures in group I was $7.5 \pm 2.8 \mathrm{mmHg}(\mathrm{N}=12)$,

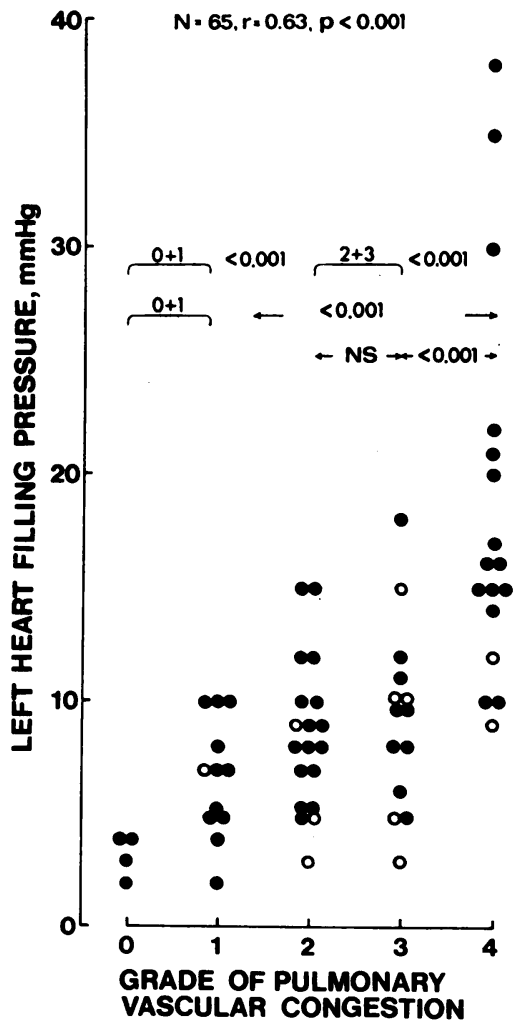

FIG. 6 LV filling pressure is related to the grade of radiological pulmonary congestion assessed from chest $\mathrm{x}$-ray films. 
and the pulmonary capillary wedge never exceeded Io $\mathrm{mmHg}$. In group 2 it was $13.1 \pm 3.7 \mathrm{mmHg}$ (range 8 to $20, N=9$ ), and in group 3 it was $25 \cdot 1 \pm 9 \cdot 2 \mathrm{mmHg}$ (range 15 to $38, \mathrm{~N}=7$ ). The individual clinical groups differed significantly from each other too: $I$ and 2, P $<0.01 ; 2$ and 3, $\mathrm{P}<0.05$, $I$ and $3, P<0.01$.

Pulmonary râles correlated with raised pulmonary capillary wedge $(P<0.001)$ in 80 comparisons. If no râles were heard, the filling pressure was usually normal, i.e. 10 $\mathrm{mmHg}$ or less, with only 4 exceptions among 45 comparisons (Fig. 7). By contrast, it did not prove possible to predict the level of pulmonary capillary wedge in a given patient in whom râles were heard. Radiologically, all patients with pulmonary oedema had râles, and patients with $x$-ray grades $O$ and $I$ had audible râles only once. However,

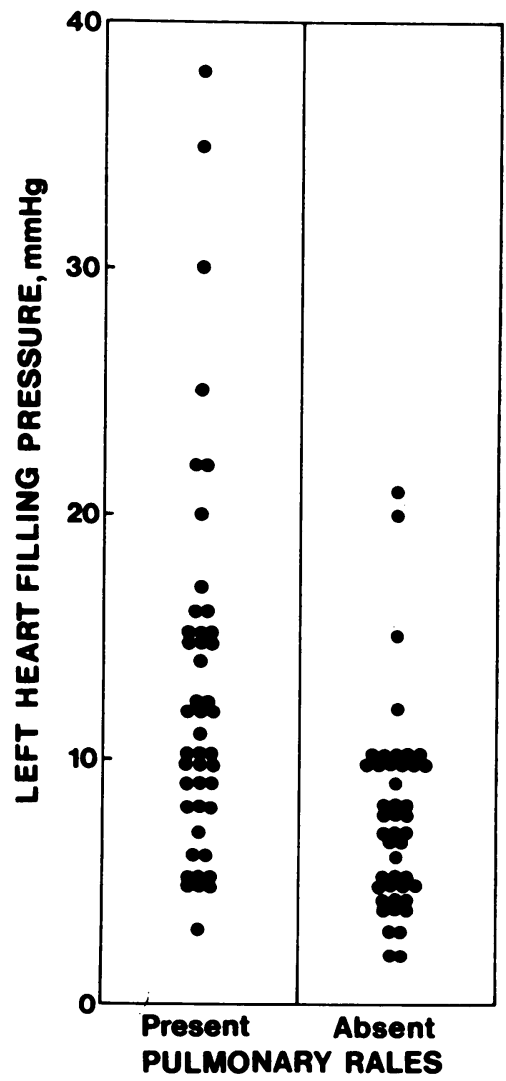

FIG. 7 Relation of pulmonary râles on auscultation to mean $L V$ filling pressure. Absence of râles indicates normal $L V$ filling pressure. great difficulties occurred in patients with grade 3 congestion, where râles were frequently absent. Thus, absence of râles correlated better with a normal pulmonary capillary wedge than with the radiological picture.

An atrial gallop was heard in 26 patients and a ventricular gallop in 33 patients. If $S_{3}$ or $S_{4}$ gallop was absent ( 5 and 12 patients) pulmonary capillary wedge pressure remained always normal and all except for 2 of these patients belonged to group I. In all other patients both the atrial and the ventricular gallop was distributed quite equally among those with normal and those with raised filling pressures. Of the 29 patients with acute myocardial infarction, I4 developed clinically detectable acute papillary muscle dysfunction. In the patients with even temporary mitral incompetence an abnormal $P$ terminal force was more frequent (Fig. 8). In fact it was abnormal in 30 instances with the mitral systolic murmurs and normal on only Io occasions.

\section{Discussion}

Correlation of electrocardiogram and LV filling pressure

The data obtained in the present study indicate that the level of the mean left atrial pressure and its serial changes, as monitored by pulmonary wedge or pulmonary arterial diastolic pressures, are closely correlated with the terminal force of the $P$ wave in lead VI of the electrocardiogram.

The results appear to provide the clinician with an external noninvasive method as a useful tool for the sequential assessment of the haemodynamic state of the left ventricle.

In acute myocardial infarction sequential changes in the LV filling pressure may occur over a wide range within a few minutes or hours. These changes in preload reflect rapid alterations in left ventricular contractile performance (Brachfeld, 1969; Hood, 197I). Thus acute variations in the $P$ wave recorded from a standard praecordial lead appear to relate quantitatively to the severity of acute changes in the state of cardiac function. Previously, the same electrocardiographic evidence of left atrial overload has been shown to provide significant prognostic value in acute infarction (Heikkilä, 1967; Heikkilä and Luomanmäki, 1970).

Left ventricular failure and the consequent distension of the left atrium results in posterior rotation and increase in magnitude of the atrial vector (Sano, Hellerstein, and Vayda, 1957; Martins de Oliviera and Zimmerman, 1959; Sutnick and Soloff, I962). This rotation is particularly notable 


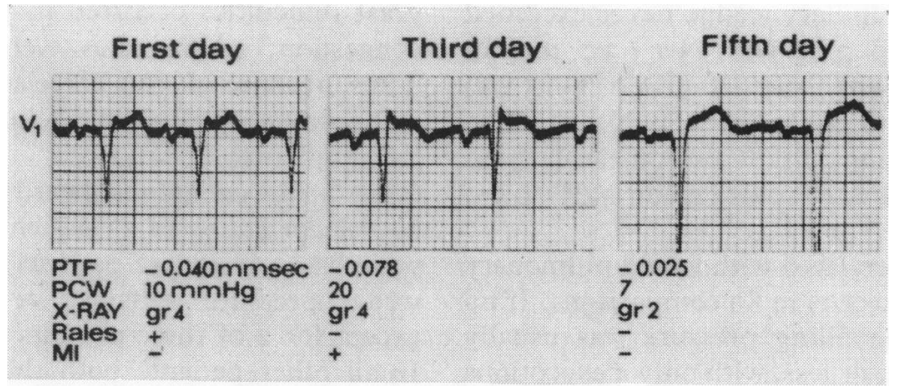

F I G. 8 Sequential alterations of $P$ terminal force predict the course of underlying haemodynamic dysfunction in acute myocardial infarction.

in the horizontal plane and is directly indicated by deepening of the negative deflection of the $P$ wave in lead VI (Morris et al., 1964).

Recent experimental evidence that acute changes in the electrical resistivity of left atrial blood are related to changes in peak spatial magnitude of the $P$ wave $(r=0.89 ; P<0.001$; Fig. 9) and the fact that changes in the resistivity of ventricular blood have similar effects on the QRS spatial vector (Nelson et al., 1972) have suggested that altered blood resistivity or its closely related causative factor, altered haematocrit, might be a pathophysiological mechanism for the observed alterations in $\mathbf{P}$ terminal force
(Hugenholtz, Heikkilä, and Nelson, 1972). Since the spread of atrial activation is largely tangential, increased haematocrit would tend to increase these tangential forces and thus $P$ terminal force. The theoretical possibility that there are such sudden changes in haematocrit as a result of sequestration of the circulating body fluids in various compartments, e.g. pulmonary oedema, warrants further investigation.

Earlier observations on the LV failure and on the influence of acute papillary muscle dysfunction in acute myocardial infarction, lend support to another explanation, that sudden increases and decreases in

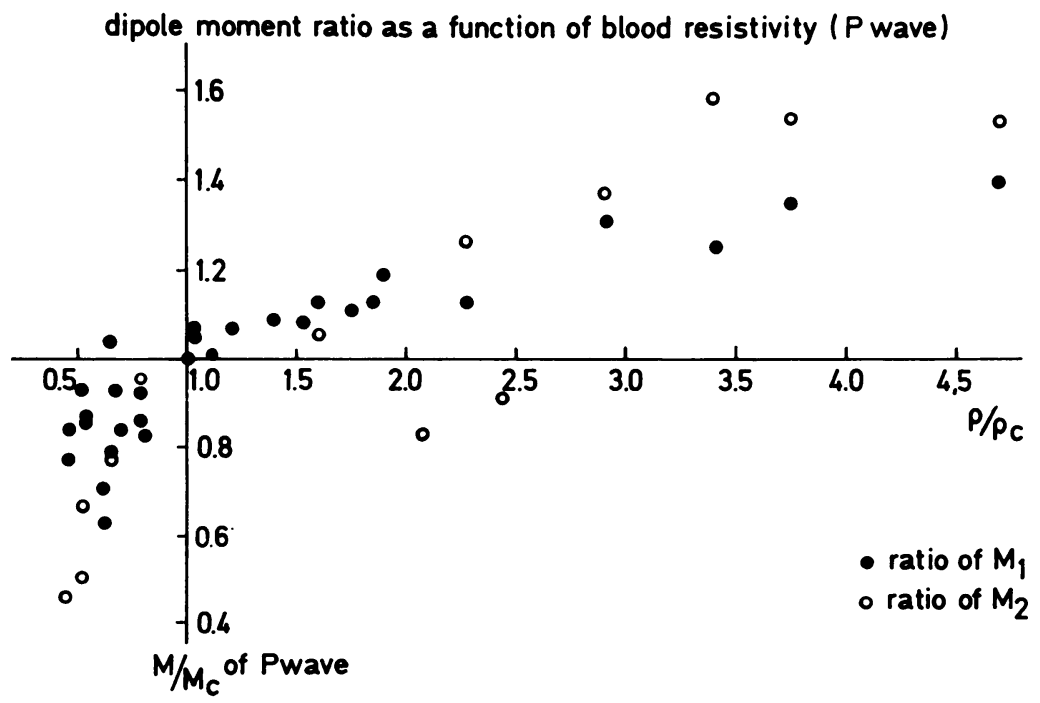

FIG. 9 Relation between dipole moment $M / M c$ of $P$ wave and blood resistivity ( $p$ ), inside left atrium of dogs. As resistivity is augmented, $P$ increases and vice versa. 
left atrial volume could be a relevant mechanism (Heikkilä, 1967; Heikkilä and Luomanmäki, 1970). Sudden increases in left atrial wall stretch by pressure rise could cause delayed activation and hence altered cancellation. This would tend to augment the influence of the left atrial vectors. However, plot of the duration $(0.04$ to $0.08 \mathrm{sec})$ against the amplitude of the terminal deflection of the $P$ wave in VI, i.e. the two components of P terminal force, failed to indicate that an increased duration (and hence decreased cancellation by right atrial depolarization) was the cause of the augmentation of $P$ terminal force. Finally, the observation that the changes occur within hours clinically, and instantaneously in an experimental study, appears to exclude atrial muscle hypertrophy as a mechanism.

Left ventricular dysfunction occurs in every patient with transmural acute myocardial infarction (Hikkilä et al., 1971a). The extent of this dysfunction is chiefly governed by the amount of muscle fibres destroyed, the degree of asynergy of ventricular contraction, the change in cardiac compliance, and the added burden of mitral regurgitation caused by papillary muscle dysfunction (Swan et al., 1970a; Heikkilä et al., I971a; Heikkilä, 1971 ; Forrester et al., 1971a). All these acute changes contribute to the rise of LV filling pressure, and thus of left atrial pressure and may eventually lead to pulmonary congestion.

As preload, reflected by pulmonary capillary wedge, is one of the most important determinants of the myocardial performance, frequent determination of $\mathrm{LV}$ filling pressure has great clinical importance in the evaluation of the adequacy of pump function in acute myocardial infarction (Fluck et al., 1967; Bradley, Jenkins, and Branthwaite, 1970; Rutherford, McCann, and O'Donovan, 1971). Clearly, the widely used method of monitoring central venous pressure, while valuable in guiding fluid replacement (Gunnar et al., 1968), does not provide meaningful information about the function of the left ventricle. Directly assessed LV filling pressure when the left ventricle is acutely damaged is the only correct determinant of left ventricular preload presently available at the bedside (Cohn, Khatri, and Hamosh, 1970; Swan et al., 1970a; Diamond et al., 197I; Forrester et al., r97Ib; Hamosh and Cohn, I97I ; Rahimtoola et al., 1971; Resnekov and Lipp, 1971). The present method is advocated as an adjunct and as an early warning system in acutely ill patients where pulmonary pressure monitoring is not available. Its only drawback appears to be in patients with existing atrial hypertrophy as in mitral stenosis, arterial hypertension, aortic valvar disease, and chronic congestive heart failure (Sutnick and Soloff, 1962;
Gooch et al., 1966; Tarazi et al., 1966; Saunders et al., 1967), and self-evidently it is not applicable in a case of atrial fibrillation. However, even in these patients (atrial fibrillation excepted) superimposed acute changes in filling pressure were closely paralleled by the $P$ wave alteration (Fig. 2). Another noninvasive method, that of measurement of LV ejection time, mainly provides a reflection of the LV stroke output and does not so clearly relate to LV filling pressure (Heikkilä, Luomanmäki, and Pyörälä, I97Ib; Rahimtoola et al., 197I).

\section{Other correlations with pulmonary capillary wedge pressure}

Chest $x$-ray film The quantitative contribution of the portable chest $x$-ray film to assess the efficacy of cardiac performance is not sufficiently appreciated in coronary care units. The correlation between the radiological appearance of venous distension and LV filling pressure has been well established earlier (Grainger, 1958; Lavender et al., 1962; Uhley et al., 1962; Logue, Rogers, and Gay, 1963; Milne, 1963; West, 1965, 1966; Hurst and Logue, 1970). A very good correlation between pulmonary capillary wedge and the radiologically assessed pulmonary vascular congestion due to left heart failure is also evident from the present data. It is notable that the finding of normal lung fields is quite exceptional in acute stages of acute myocardial infarction, as pulmonary venous distension presents itself immediately after an increase in the mean LV filling pressure above Io $\mathrm{mmHg}$ (Logue et al., I963; Heikkilä, 1967; Heikkilä et al, 1971a). Despite the statement by Sjögren (1970) that auscultatory râles are more indicative of an increased pulmonary capillary wedge pressure than are $x$-ray findings, neither the present results nor those of others on LV filling pressure in acute myocardial infarction (Lassers et al., 1970; Forrester et al., I97Ib; Hamosh and Cohn, 197I) confirm this.

On the other hand, radiological changes are much slower in their onset or disappearance than changes in P terminal force. This is one likely reason for the higher correlation coefficient between pulmonary capillary wedge and $\mathbf{P}$ terminal force than that between pulmonary capillary wedge and pulmonary venous congestion found only in acute situations. Indeed, the slow, 'out of phase' disappearance of interstitial fluid gave a picture of serious interstitial oedema for 12 to 24 hours after LV filling pressure had returned to normal as the result of treatment. Similarly, the development of acute haemodynamic deterioration will be more rapidly reflected in pulmonary capillary wedge and $P$ terminal force. In addition to the fact that good chest films are logistic- 
ally difficult to obtain, determination of $P$ terminal force has the advantage of being a sensitive monitor of the adequacy of fluid therapy in terms of an optimal filling pressure of the left side of the heart.

\section{Clinical and haemodynamic correlations}

A rise in the LV end-diastolic pressure has been reported to occur in the majority of patients with acute myocardial infarction even when uncomplicated (Hunt et al., I970; Hamosh and Cohn, I97I; Karliner and Ross, 197I ; Rahimtoola et al., 1971). However, the mean ('pre-a') LV filling pressure and the mean left atrial pressure has a closer association with the development of pulmonary venous hypertension than the higher but instantaneous LV end-diastolic pressure which is greatly influenced by alteration of myocardial compliance. The present data of development of clinical, electrocardiographic, and $x$-ray signs of LV failure in acute myocardial infarction provide support for this concept. For example, atrial gallop is at times present in every patient with acute myocardial infarction and sinus rhythm (Hill et al., 1969; Heikkilä et al., 1971a). Thus, it is not surprising that the development of an $\mathrm{S}_{4}$ in acute myocardial infarction is neither correlated with $\mathrm{LV}$ filling pressure, nor with $\mathrm{P}$ terminal force or any other clinical or radiological sign of left ventricular failure (Heikkilä and Luomanmäki, 1970). Again, the absence of $S_{3}$ gallop, as does that of $\mathrm{S}_{4}$ or pulmonary moist râles, strongly indicates normal LV filling pressure, but the finding of each of these auscultatory signs may be noted in our experience with normal as well as with raised LV diastolic pressure in acute myocardial infarction.

In conclusion, though considerable overlap is frequently reported between clinical and haemodynamic parameters in acute myocardial infarction (Ramo et al., 1970; Resnekov and Lipp, 197I), a remarkably good prediction of the normality or alternatively of the important rise in mean LV filling pressure, seems to be possible by careful clinical, electrocardiographic, and radiological bedside methods.

We are most grateful to Miss Delores Paladino, R.N., Head Nurse of the Coronary Care Unit, whose willing help and co-operation greatly contributed to the clinical management and to the haemodynamic studies of the patients included in this series.

\section{References}

Brachfeld, N. (1969). Maintenance of cell viability. Circulation, 40, Suppl. 4, 202.

Bradley, R. D., Jenkins, B. S., and Branthwaite, M. A. (1970). The influence of atrial pressure on cardiac performance following myocardial infarction complicated by shock. Circulation, 42, 827.
Cohn, J. N., Khatri, I. M., and Hamosh, P. (1970). Bedside catheterization of the left ventricle. American fournal of Cardiology, 25, 66.

Diamond, G., Marcus, H., McHugh, T., Swan, H. J. C., and Forrester, J. (197I). Catheterization of left ventricle in acutely ill patients. British Heart fournal, 33, 489.

Fluck, D. C., Valentine, P. A., Treister, B., Higgs, B., Reid, D. N., Steiner, R. E., and Mounsey, J. P. D. (1967). Right heart pressures in acute myocardial infarction. British Heart fournal, 29, 748.

Forrester, J. S., Diamond, G., Freedman, S., Allen, H. N., Parmley, W. W., Matloff, J., and Swan, H. J. C. (I97Ia). Silent mitral insufficiency in acute myocardial infarction. Circulation, 44, 877.

Forrester, J. S., Diamond, G., McHugh, T. J., and Swan, H. J. C. (I97Ib). Filling pressures in the right and left sides of the heart in acute myocardial infarction. New England fournal, of Medicine, 285, 190.

Gooch, A. S., Calatayud, J. B., Rogers, J. B., and Gorman, P. A. (1966). Analysis of the P-wave in severe aortic stenosis. Diseases of the Chest, 49, 459.

Grainger, R. G. (1958). Pulmonary hypertension: A symposium. III. Interstitial pulmonary oedema and its radiological diagnosis. A sign of pulmonary venous and capillary hypertension. British fournal of Radiology, 31, 201.

Gunnar, R. M., Loeb, H. S., Pietras, R. J., and Tobin, J. R. (1968). Hemodynamic measurements in a coronary care unit. Progress in Cardiovascular Diseases, II, 29.

Hamosh, P., and Cohn, J. N. (197I). Left ventricular function in acute myocardial infarction. Fournal of Clinical Investigation, 50, 523.

Heikkilä, J. (1967). Mitral incompetence as a complication of acute myocardial infarction. Acta Medica Scandinavica, 182, Suppl. 475.

Heikkilä, J. (I97I). The fate of mitral valve complex in acute myocardial infarction. Annals of Clinical Research, 3, 386.

Heikkilä, J., and Luomanmäki, K. (1970). Value of serial Pwave changes in indicating left heart failure in myocardial infarction. British Heart fournal, 32, 510.

Heikkilä, J., Luomanmäki, K., and Pyörälä, K. (I971a). Serial observations on left ventricular dysfunction in acute myocardial infarction. I. Gallop sounds, ventricular asynergy and radiological signs. Acta Medica Scandinavica, r90, 89.

Heikkilä, J., Luomanmäki, K., and Pyörälä, K. (I97Ib). Serial observations on left ventricular dysfunction in acute myocardial infarction. II. Systolic time intervals in power failure. Circulation, 44, 343.

Hill, J. C., O'Rourke, R. A., Lewis, R. P., and McGranahan, G. M. (1969). The diagnostic value of the atrial gallop in acute myocardial infarction. American Heart fournal, 78, I94.

Hood, W. B., Jr. (1971). Pathophysiology of ischemic heart disease. Progress in Cardiovascular Diseases, 14, 297.

Hugenholtz, P. G., Heikkilä, J., and Nelson, C. V. (1972). Prediction of acute changes in left atrial hemodynamics from the P-wave. American fournal of Cardiology, 29, 270.

Hunt, D., Potanin, C., Pombo, J., Russell, R. O., Jr., and Rackley, C. E. (1970). Left ventricular function in clinically uncomplicated myocardial infarction (abstract). Clinical Research, 18, 313.

Hurst, J. W., and Logue, R. B. (1970). The Heart, and ed. McGraw-Hill, New York.

Karliner, J. S., and Ross, J., Jr. (197I). Left ventricular performance after acute myocardial infarction. Progress in Cardiovascular Diseases, 13, 374.

Kasser, I., and Kennedy, J. W. (1969). The relationship of increased left atrial volume and pressure to abnormal Pwaves on the electrocardiogram. Circulation, 39, 339. 
Lassers, B. W., George, M., Anderton, J. L., Higgins, M. R., and Philp, T. (1970). Left ventricular failure in acute myocardial infarction. American fournal of Cardiology, 25, 51 I.

Lavender, J. P., Doppman, J., Shawdon, H., and Steiner, R. E. (1962). Pulmonary veins in left ventricular failure and mitral stenosis. British fournal of Radiology, 35, 293.

Logue, R. B., Rogers, J. V., Jr., and Gay, B. B., Jr. (1963). Subtle roentgenographic signs of left heart failure. American Heart fournal, 65, 464.

Martins de Oliviera, J., and Zimmerman, H. A. (1959). Auricular overloadings. Electrocardiographic analysis of I93 cases. American fournal of Cardiology, 3, 453.

Milne, E. N. C. (1963). Physiological interpretation of the plain radiograph in mitral stenosis, including a review of criteria for the radiological estimation of pulmonary arterial and venous pressures. British fournal of Radiology, 36, 902 .

Morris, J. J., Jr., Estes, E. H., Jr., Whalen, R. E., Thompson, H. K., Jr., and McIntosh, H. D. (I964). P-wave analysis in valvular heart disease. Circulation, 29, 242.

Nelson, C. V., Rand, P. W., Angelakos, E. T., and Hugenholtz, P. G. (1972). Effect of intracardiac blood on the spatial vectorcardiogram. Circulation Research, 31, 95.

Rahimtoola, S. H., DiGilio, M. M., Sinno, M. Z., Loeb, H. S., Rosen, K. M., and Gunnar, R. M. (197I). Cardiac performance three to eight weeks after acute myocardial infarction. Archives of Internal Medicine, 128, 220.

Ramo, B. W., Myers, N., Wallace, A. G., Starmer, F., Clark, D. O., and Whalen, R. E. (1970). Hemodynamic findings in 123 patients with acute myocardial infarction on admission. Circulation, 42, 567.

Resnekov, L., and Lipp, H. (I97I). Circulatory effects of acute myocardial infarction as a rational basis for therapy. Annals of Clinical Research, 3, 362.

Russell, R. O., Jr., Rackley, C. E., Pombo, J., Hunt, D., Potanin, C., and Dodge, H. T. (1970). Effects of increasing left ventricular filling pressure in patients with acute myocardial infarction. Fournal of Clinical Investigation, 49, 1539.
Rutherford, B. D., McCann, W. D., and O'Donovan, T. P. B. (197I). The value of monitoring pulmonary artery pressure for early detection of left ventricular failure following myocardial infarction. Circulation, 43, 655 .

Sano, T., Hellerstein, H. K., and Vayda, E. (1957). P vector loop in health and disease as studied by the technique of electrical dissection of the vectorcardiogram (differential vectorcardiography). American Heart fournal, 53, 854 .

Saunders, J. L., Calatayud, J. B., Schulz, K. J., Maranhao, V., Gooch, A. S., and Goldberg, H. (1967). Evaluation of ECG criteria for P-wave abnormalities. American Heart fournal, 74, 757 .

Sjögren, A. (1970). Left heart failure in acute myocardial infarction. Acta Medica Scandinavica, 188, Suppl. 5 Io.

Sutnick, A. I., and Soloff, L. A. (1962). Posterior rotation of the atrial vector. An electrocardiographic sign of left ventricular failure. Circulation, 26, 913.

Swan, H. J. C., Forrester, J. S., Danzig, R., and Allen, H. N. (I970a). Power failure in acute myocardial infarction. Progress in Cardiovascular Diseases, 12, 568.

Swan, H. J. C., Ganz, W., Forrester, J., Marcus, H., Diamond, G., and Chonette, D. (1970b). Catheterization of the heart in man with use of a flow-directed balloon-tipped catheter. New England fournal of Medicine, 283, 447.

Tarazi, R. C., Miller, A., Frohlich, E. D., and Dustan, H. P. (1966). Electrocardiographic changes reflecting left atrial abnormality in hypertension. Circulation, 34, 818 .

Uhley, H. N., Leeds, S. E., Sampson, J. J., and Friedman, M. (1962). Role of pulmonary lymphatics in chronic pulmonary edema. Circulation Research, 11, 966.

West, J. B. (1965). Perivascular edema, a factor in pulmonary vascular resistance. American Heart fournal, 70, 570.

West, J. B. (1966). Influence of hydrostatic pressure in the pulmonary circulation. Symposium on pulmonary circulation. Fapanese Heart fournal, 7, 350.

Requests for reprints to Dr. Juhani Heikkilä, Cardiovascular Laboratory, First Department of Medicine, University Central Hospital, 00290 Helsinki 29, Finland. 